The University of Maine

DigitalCommons@UMaine

Maine-Syracuse Longitudinal Papers

Maine-Syracuse Longitudinal Study

2000

\title{
Low Blood Pressure and Depression: Comorbidity and Competing Outcomes
}

Michael A. Robbins

University of Maine - Main, robbins@maine.edu

Penelope K. Elias

Merrill F. Elias

University of Maine - Main, mfelias@maine.edu

Follow this and additional works at: https://digitalcommons.library.umaine.edu/ longitudinal_papers

Part of the Cardiovascular System Commons, and the Health Psychology Commons

\section{Repository Citation}

Robbins, M. A., Elias, P. K., \& Elias, M. F. (2000). Low blood pressure and depression: Comorbidity and competing outcomes. Journal of the American Geriatrics Society, 48, 336-337.

This Editorial is brought to you for free and open access by DigitalCommons@UMaine. It has been accepted for inclusion in Maine-Syracuse Longitudinal Papers by an authorized administrator of DigitalCommons@UMaine. For more information, please contact um.library.technical.services@maine.edu. 


\section{Low Blood Pressure and Depression: Comorbidity and Competing Outcomes}

$\mathrm{T}$ he study by Stroup-Benham et al. ${ }^{1}$ makes several important contributions to the literature on depressive symptom-reporting in relation to blood pressure (BP). Their findings support the existence of an association between low $\mathrm{BP}$ and higher levels of depressive symptomatology and a constellation of somatic and psychosocial variables. Their study design took into consideration important variables that must be controlled when examining these relationships. Analyses were conducted with statistical adjustment for the effects of possible confounders, including gender, age, marital status, obesity, self-reported diagnosis of hypertension, current use of antihypertensive medication, and current use of central nervous system active medication.

Stroup-Benham et al. measured depressive symptoms with the Center for Epidemiological Studies-Depression Scale (CES-D), ${ }^{2}$ a well validated self-report measure. In contrast, several earlier studies examined only a few specific symptoms associated with depression. Results of the Stroup-Benham et al. study for an older Mexican-American sample are consistent with results obtained in samples with different age ranges and other ethnic groups. Because there is evidence that cultural belief systems are relevant to depression, ${ }^{3}$ this additional evidence of generalizability across ethnic groups is important. Their findings are also consistent with the continental European medical view with respect to BP, that is, lower is not necessarily better. ${ }^{4}$ However, it is important to note that hypotension was defined by Stroup-Benham et al, as systolic BP less than $120 \mathrm{~mm} \mathrm{Hg}$ or diastolic BP less than 75 $\operatorname{mm} \mathrm{Hg}$.

Using this definition, both systolic hypotension and diastolic hypotension were associated with higher levels of selfreported depressive symptoms for their large sample of Mexican-American women and men aged 65 and older. Individuals whose systolic and diastolic BP values were both in the hypotensive range were particularly at risk for scores in the depressed range (CES-D score $\geq 16$ ), for lower selfesteem, and for reporting problems with waking up feeling tired. The comparison group comprised normotensives (systolic BP of 120 to $139 \mathrm{~mm} \mathrm{Hg}$; diastolic of 75 to $84 \mathrm{~mm} \mathrm{Hg}$ ) for all analyses. The depression scores for individuals with elewated BP values were reported as intermediate between those for individuals described as hypotensive and those described as normotensive.

The similarity of this curvilinear association between BP and depression to reports of $\mathrm{J}$ - or U-shaped functions between BP and mortality ${ }^{5,6}$ and cognitive functioning ${ }^{7}$ is of interest and raises the following issues: (1) what is the optimal goal for blood pressure lowering with anthypertensive treatment when psychological as well as medical goals, e.g*y teduction of stroke, are considered; (2) is age an important consideration in relation to associations between $\mathrm{BP}$ and outcome measures such as depression, mortality, and cognitive functioning?

It is clear that the findings reported by Stroup-Benham et al. are not attributable to lowering of BP via current antihypertensive medication use. These investigators were careful to point out that their results should not be construed as indicating that treatment designed to increase $\mathrm{BP}$ values might be beneficial in reducing levels of depressive symptoms. However, they did suggest that their results indicate that there may be an optimal cut point for defining "well controlled" BP. A question may be raised as to whether this cut point is dictated by $\mathrm{BP}$ level or by the amount, or types, of medication required to reduce BP.

Indeed, there is a commonality between the possible side effects related to medication use and the symptoms associated with both hypotension and depression. Among the side effects most commonly associated with antihypertensive medications are drowsiness, weakness, fatigue, and impaired concentration and memory. 8,9 Thus, lowering $B P$ to the point of hypotension might affect depression via the low BP levels, increased sideeffects from higher dosages of medication, or both.

\section{See also $\mathbf{p} 250$}

However, the definition of hypotension used by StroupBenham et al. may not commonly be accepted as such by the healthcare community. The BP ranges defined as hypotensive by Stroup-Benham et al. correspond closely to the ranges classified as optimal (SBP values less than $120 \mathrm{~mm} \mathrm{Hg}$ and DBP values less than $80 \mathrm{~mm} \mathrm{Hg}$ ) in the Sixth Report of the Joint National Committee (JNC) on Prevention, Detection, and Treatment of High Blood Pressure. ${ }^{10}$ The JNC report does caution that unusually low BP values should be evaluated for clinical significance, but no criteria are given. The initial goal for treatment advocated in the JNC report is to lower BP into the normotensive range (SBP less than $140 \mathrm{~mm}$ $\mathrm{Hg}$ and DBP less than $90 \mathrm{~mm} \mathrm{Hg}$ ). Further lowering of BP, if tolerated by the patient, is recommended primarily "to prevent stroke, to preserve renal function, and to prevent or slow heart failure progression" (p. 20). Most would agree that these are high priority objectives. Clearly, the range of $\mathrm{BP}$ values optimal with respect to reducing risk for some possible outcomes (e. g., stroke) may not be optimal for other outcomes (e.g., depression). Therefore, one must consider the risk from the perspective of competing outcomes. For example, can we tolerate some depression to reduce the likelihood of stroke, an often catastrophic event? From this perspective, the age of the patient becomes a major consideration.

In the Stroup-Benham study, low BP level was associated with greater symptoms of depression for both age groups (65 
to 74 years; 75 years or older), and the JNC report does not propose different target levels for $\mathrm{BP}$ depending on age. However, some studies do indicate that age is an important consideration with respect both to $\mathrm{BP}$ lowering ${ }^{11}$ and to symptoms of depression and other psychological variables. ${ }^{12,13}$ Orthostatic hypotension caused by antihypertensive medication use may be more common, and is also more serious, in older persons because of their increased risk of major injury (e.g., hip fracture) during syncope. ${ }^{11}$ Some studies have shown that somatic symptoms (or correlates) of depression such as lowered energy levels and disturbances in sleep and appetite are more common in older people. ${ }^{14,15}$

Stroup-Benham et al. suggest that individuals with low BP may represent two populations. They speculate that their low BP sample might consist of individuals who represent a healthy population as well as chronically-ill individuals with higher levels of depressive symptoms and a higher risk of mortality. This is an important point because for some individuals, low BP may be the consequence of disease. Disease, in turn, impacts negatively on mortality, cognitive functioning, and psychological variables, including depression. ${ }^{16,17}$

As is true of high BP, low BP can be viewed as the common outcome of diverse processes. Increased risk for depression, cognitive impairment, and mortality might be specific to low BP that is concurrent with or secondary to other disease processes. If so, withholding treatment that wonld keep BP within optimal ranges (systolic BP less than $120 \mathrm{~mm} \mathrm{Hg}$ and diastolic BP less than $80 \mathrm{~mm} \mathrm{Hg}$ ) may, for many patients, not pose a solution to depression, and it may increase the risk of other adverse outcomes such as stroke and coronary heart disease. ${ }^{18,19}$ These adverse outcomes may then potentiate the problem with respect to depression. This point is arguable and, hopefully, a stimulus to further research. But it seems clear that treatment must take into account multiple outcomes, and outcomes must be assigned priorities based on the patient's age, unique risk profile, and medical history. Professor D. H. P. Streeten and colleagues argue this point with simplicity and elegance: "No population studies, of whatever size, will ever obviate the need for considering individual factors in making therapeutic decisions on patients with hypertension" 11 (p. 97).

$$
\begin{array}{r}
\text { Michael A. Robbins, PhD } \\
\text { Department of Psychology } \\
\text { University of Maine, Orono, Maine } \\
\text { Penelope K. Elias, PhD } \\
\text { Department of Matbematics and Statistics } \\
\text { Boston University, Boston, Massachusetts }
\end{array}
$$

Merrill F. Elias, PhD, MPH

Department of Psychology, University of Maine Department of Mathematics and Statistics

Boston University

\section{REFERENCES}

1. Stroup-Benham CA, Markides KS, Black S, Goodwin JS. Relationship between low blood pressure and depressive symptonatology in older people. J Am Geriatr $S \propto c$ 2000;48:000-000.

2. Radioff $L S$. The CES-D scale: A self-report depression scale for research in the general population. Appl Psychol Meas 1977;1:385-401.

3. Gallo Jf, Cooper-Patrick $L$, Lesikar S. Depressive symptoms of whites and African-Americans aged 60 years and older. J Gerontol: Psychol $S_{c i} 1998$; 53B:P277-286.

4. Pemberton J. Does constitutional hypotension exist? BMJ 1989;298:660-662.

5. Okumiya $\mathrm{K}$, Matsuhayaşi $\mathrm{K}$, Wada T et al. A U-shaped association between home systolic blood pressure and four-year mortality in communitydwelling older men. J Am Geriatr Soc 1999;47:1415-1421.

6. Somes GW, Shorr RI, Pahor M. A new twist in the J-shape curve. I Am Geriatr Soc 1999;47:1477-1478.

7. Guo Z, Fratiglioni L, Winblad B, Viitanen M. Blood pressure and performance on the Mini-Mental State Examination in the very old. An I Epidemiol 1997;145:1106-1113.

8. Dimsdale JE. Reflections on the impact of antihypertensive medications on mood, sedation, and neuropsychologic functioning. Atch Intern Med 1992; 152:35-39.

9. Muldoon MF, Waldstein SR, Jennings JR. Neuropsychological consequences of antihypertensive medication use. Exp Aging Res 1995;21:353-368.

10. National High Blood Pressure Education Program. The Sixth Report of the Joint National Committee on Prevention, Detection, Evaluation, and Treatment of High Blood Pressure. Bethesda, MD: US Department of Health and Human Services, National Heart, Lung, and Blood Institute. NIH Publication $\mathrm{No}_{*}$ 1997:98-4080.

11. Streeten DHP, Anderson GH Jr, Elias MF. Prevalence of secondary hypertension and unusual aspects of the trearment of hypertension in elderty individuals. Geriatric Nephrol Urol 1992;2;91-98.

12. Blazer D, Burchett B, Service C, George LK. The association of age and depression among the elderly: An epidemiologic exploration. I Gerontol: Med Sci 1991;46:M210-215.

13. Gatz M, Hurwicz M-L. Are old people more depressed: Cross-sectional data on Center for Epidemiological Studies Depression Seale factors. Psychol Aging 1990,5:284-290.

14. Berry IM, Storandt M, Coyne A. Age and sex differences in somatic womplaints assaciated with depression. J Getontol 1984,39:465-467.

15. Bolla-Wilson K, Bleecker ML. Absence of depression in elderly adults. J Gerontol: Psychol Sci 1989;44:P53-55.

16. Elias MF, Elias JW, Elias PK. Biological and health influences on behavior. In: Birren JE, Schaie KW, eds. Handbook of the Psychology of aging, 3rd Ed. San Diego: Academic Press, 1990, pp 79-102.

17. Siegler IC, Costa PT Jr. Health behavior relationships, In: Birren JE, Schaie KW, eds. Handbook of the Psychology of Aging. New York: Van Nostrant Reinhold, 1985, pp 144-166.

18. Fletcher $\mathrm{AE}_{2}$ Bulpity $\mathrm{CJ}$. How far should blood pressure be lowered New Engl I Med 1992;326:251-254.

19. Wolf PA, D'Agostino RB, Belanger AJ, Kannell WB. Probability of stroke: risk factor profile from the Framingham Srudy. Stroke 1991;22,312-318. 